Corrective Action Unit Modeling Approach for the Underground Test Area, Nevada Test
Nye County,
Nevada

March 1998

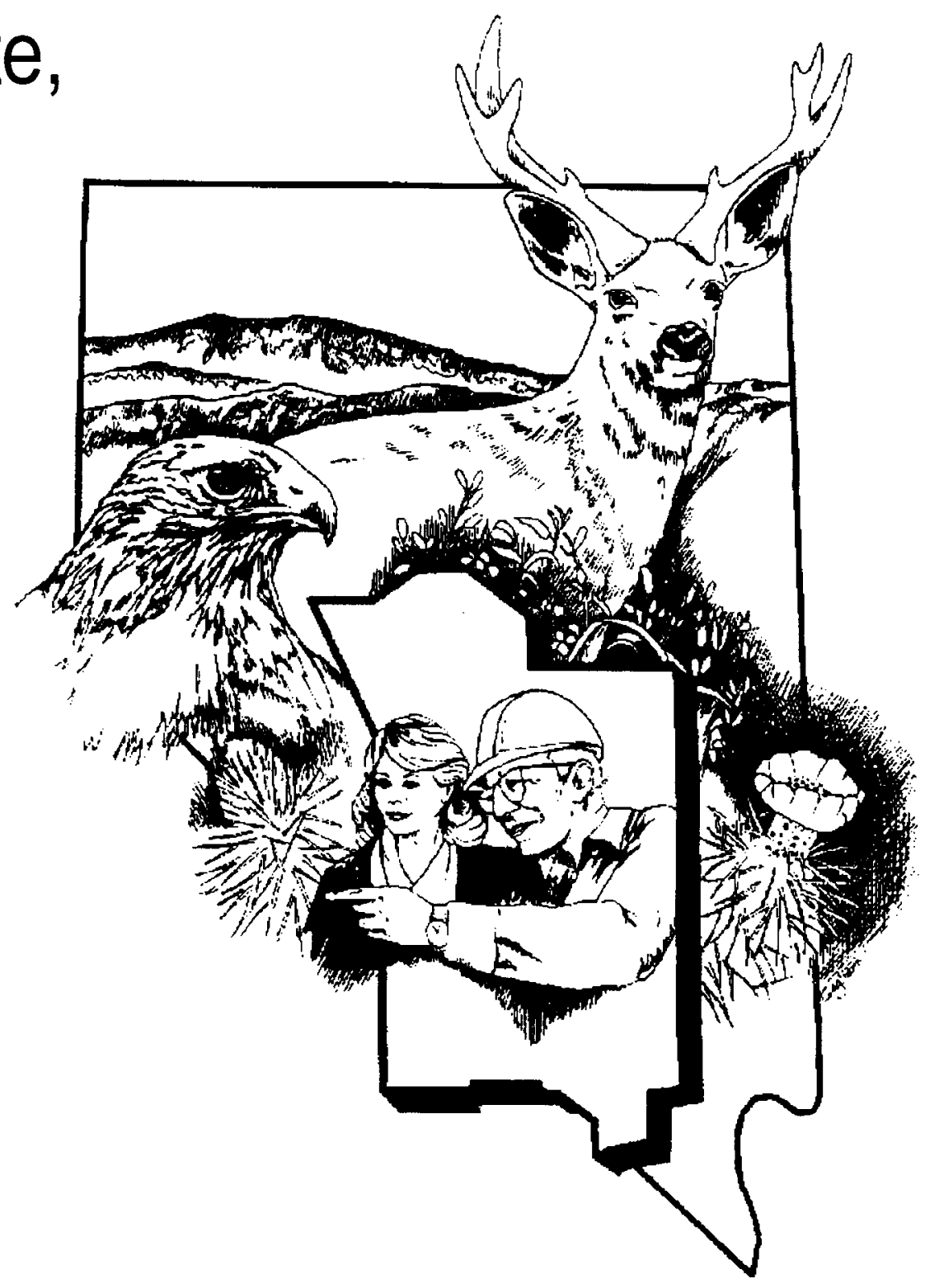




\section{CORRECTIVE ACTION UNIT MODELING APPROACH FOR THE UNDERGROUND TEST AREA, NEVADA TEST SITE, NYE COUNTY, NEVADA}

IT CORPORATION

2621 Losee Road, Bldg. B-1, Suite 3050-01

N. Las Vegas, Nevada 89030

March 1998

Prepared for the U.S. Department of Energy Nevada Operations Office under Contract No. DE-AC08-97NV13052 
This report has been reproduced directly from the best available copy.

Available to DOE and DOE contractors from the Office of Scientific and Technical Information, P.O. Box 62, Oak Ridge, TN 37831; prices available from (423) 576-8401.

Available to the public from the National Technical Information Service, U.S. Department of Commerce, 5285 Port Royal Road, Springfield, VA 22161, telephone (703) 487-4650. 


\section{CORRECTIVE ACTION UNIT MODELING APPROACH FOR THE UNDERGROUND TEST AREA, \\ NEVADA TEST SITE, NYE COUNTY, NEVADA}

Approved by: Hetereterele

Janet N. Wille

ITLV UGTA Project Manager

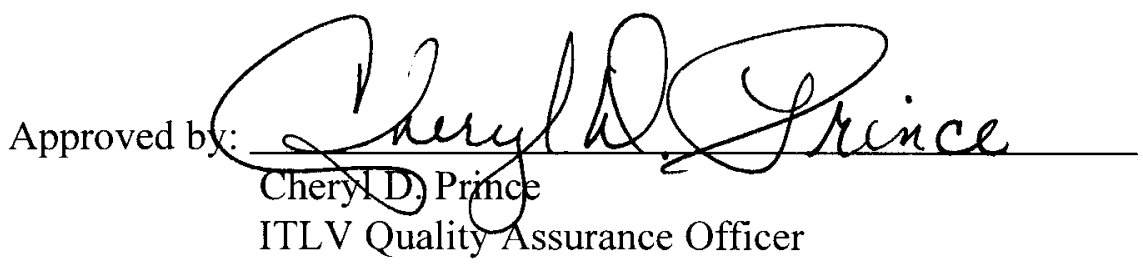

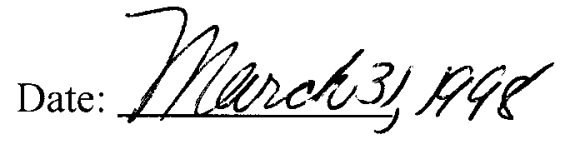

Date: $7 / 20 / 98$ 


\section{Table of Contents}

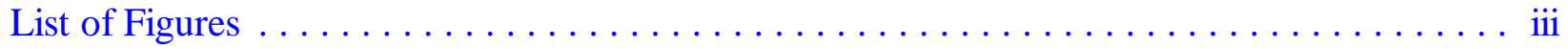

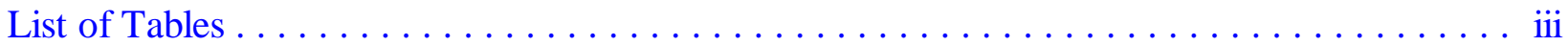

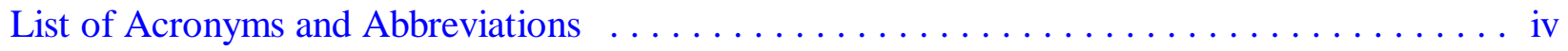

1.0 Introduction $\ldots \ldots \ldots \ldots \ldots \ldots \ldots \ldots \ldots \ldots \ldots \ldots \ldots \ldots \ldots \ldots \ldots \ldots \ldots, 1-1$

1.1 Project Background $\ldots \ldots \ldots \ldots \ldots \ldots \ldots \ldots \ldots \ldots \ldots \ldots \ldots \ldots \ldots \ldots \ldots \ldots \ldots \ldots \ldots, 1$

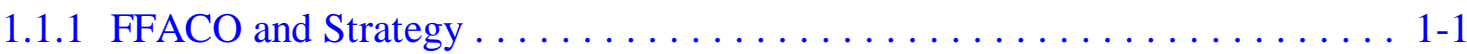

1.1.2 Role of Modeling in the FFACO Process $\ldots \ldots \ldots \ldots \ldots \ldots \ldots \ldots . .3$

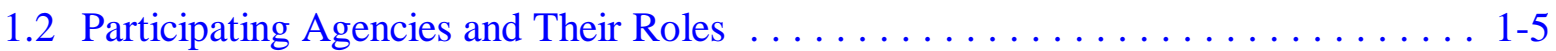

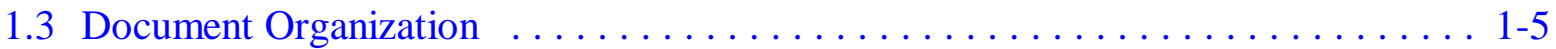

2.0 Corrective Action Unit Model Description . . . . . . . . . . . . . . . . . . . . . . 2 2-1

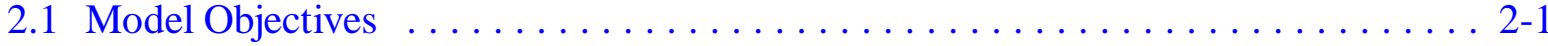

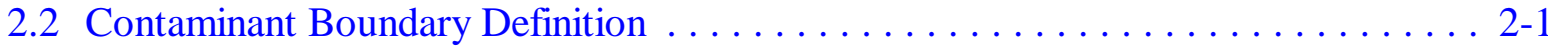

2.3 Requirements for a CAU-Scale Model ....................... 2-3

2.4 Groundwater Flow and Transport Conceptual Model $\ldots \ldots \ldots \ldots \ldots . \ldots . . \ldots 2-3$

2.5 Numerical Code Selection .............................. 2-5

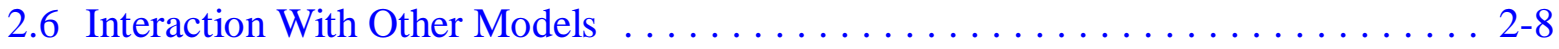

2.6.1 Regional Groundwater Flow Model $\ldots \ldots \ldots \ldots \ldots \ldots \ldots \ldots \ldots .2-8$

2.6.2 DRI Random Field Generator $\ldots \ldots \ldots \ldots \ldots \ldots \ldots \ldots \ldots \ldots \ldots .2-8$

2.6.3 LLNL Source Term Model . . . . . . . . . . . . . . . . . . . . . . . 2-9

3.0 Corrective Action Unit Model Development . . . . . . . . . . . . . . . . 3-1

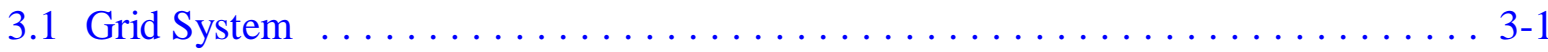

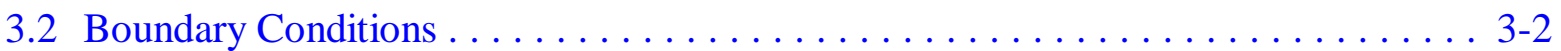

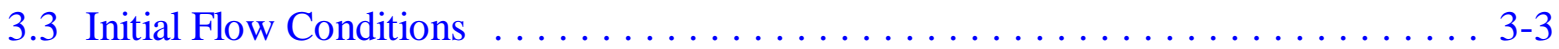

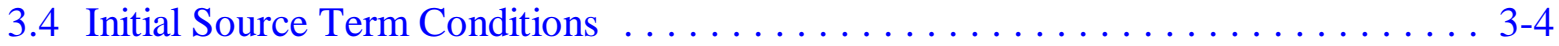

3.5 Model Calibration . . . . . . . . . . . . . . . . . . . . . . . . . 3-4

3.6 Sensitivity Analyses . . . . . . . . . . . . . . . . . . . . . . . . . . . 3

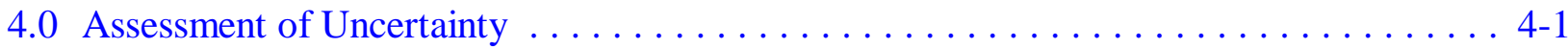


Table of Contents (Continued)

5.0 Summary of the Modeling Approach $\ldots \ldots \ldots \ldots \ldots \ldots \ldots \ldots \ldots \ldots \ldots \ldots$

6.0 References ................................. 6-1 


\section{List of Figures}

Number

Title

Page

1-1 Underground Test Area Corrective Action Units $\ldots \ldots \ldots \ldots \ldots \ldots \ldots \ldots$ 1-2

1-2 Process Flow Diagram for the Underground Test Area

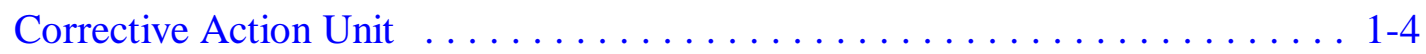

\section{List of Tables}

Number

2-1 Candidate Groundwater Flow and Transport Codes

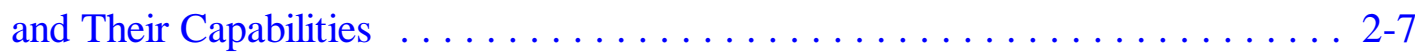




\section{List of Acronyms and Abbreviations}

$\begin{array}{ll}\text { ASTM } & \text { American Society for Testing and Materials } \\ \text { BN } & \text { Bechtel Nevada } \\ \text { CADD } & \text { Corrective Action Decision Document } \\ \text { CAP } & \text { Corrective Action Plan } \\ \text { CAS } & \text { Corrective Action Site(s) } \\ \text { CAU } & \text { Corrective Action Unit(s) } \\ \text { DOE } & \text { U.S. Department of Energy } \\ \text { DRI } & \text { Desert Research Institute } \\ \text { FFACO } & \text { Federal Facility Agreement and Consent Order } \\ \text { ft } & \text { Foot (feet) } \\ \text { HSU } & \text { Hydrostratigraphic unit(s) } \\ \text { IT } & \text { IT Corporation } \\ \text { km } & \text { Kilometer(s) } \\ \text { LANL } & \text { Los Alamos National Laboratory } \\ \text { LLNL } & \text { Lawrence Livermore National Laboratory } \\ \text { m } & \text { Meter(s) } \\ \text { mi } & \text { Mile(s) } \\ \text { mrem/yr } & \text { Millirem(s) per year } \\ \text { NTS } & \text { Nevada Test Site } \\ \text { PDF } & \text { Probability distribution function(s) } \\ \text { UGTA } & \text { Underground Test Area } \\ \text { USGS } & \text { U.S. Geological Survey } \\ & \end{array}$




\subsection{Introduction}

The modeling approach serves as a template for the development, application, and interpretation of the Corrective Action Unit (CAU) - scale saturated groundwater flow and transport model (herein called the CAU model) to be used for forecasting radionuclide migration in all Nevada Test Site (NTS) CAUs, consistent with the Federal Facility Agreement and Consent Order (FFACO) and Underground Test Area (UGTA) strategy. A summary of the project background, the FFACO and strategy, and the roles of participating agencies, is provided followed by a description of the contents of the document.

\subsection{Project Background}

The first part of the UGTA subproject was a regional evaluation which was recently completed (DOE, 1997). During the regional evaluation, a groundwater flow model representative of Nevada Test Site regional conditions and a site-specific transport model were developed and used to determine if any immediate risks to human health and the environment exist. The second part of the investigation consists of several local studies focused on estimating contaminant movement and developing boundaries that encompass the extent of contaminant migration from the underground testing areas. The strategy for completing the second part of the investigation is detailed in the Federal Facility Agreement Consent Order (FFACO) (1996).

\subsubsection{FFACO and Strategy}

The FFACO (1996) serves as the regulatory driver of work conducted under the UGTA subproject. As a part of the FFACO, Underground test areas at the Nevada Test Site have been grouped into the following Corrective Action Units: Yucca Flat, Frenchman Flat, Western Pahute Mesa, Central Pahute Mesa, Rainier Mesa/Shoshone Mountain, and Climax Mountain (Figure 1-1). Each CAU includes a group of Corrective Action Sites (CASs) corresponding to underground nuclear tests. A total number of 878 CASs were identified at the Nevada Test Site (Figure 1-1). The Yucca Flat CAU includes 717 of these CASs, Frenchman Flat includes 10, Western Pahute Mesa includes 18, Central Pahute Mesa includes 64, the Rainier Mesa/Shoshone Mountain area include 66, and the Climax Mountain area includes three (FFACO, 1996).

Appendix VI of the FFACO (1996) details the strategy that the U.S. Department of Energy will use to achieve closure of the underground nuclear test Corrective Action Units. The objective 


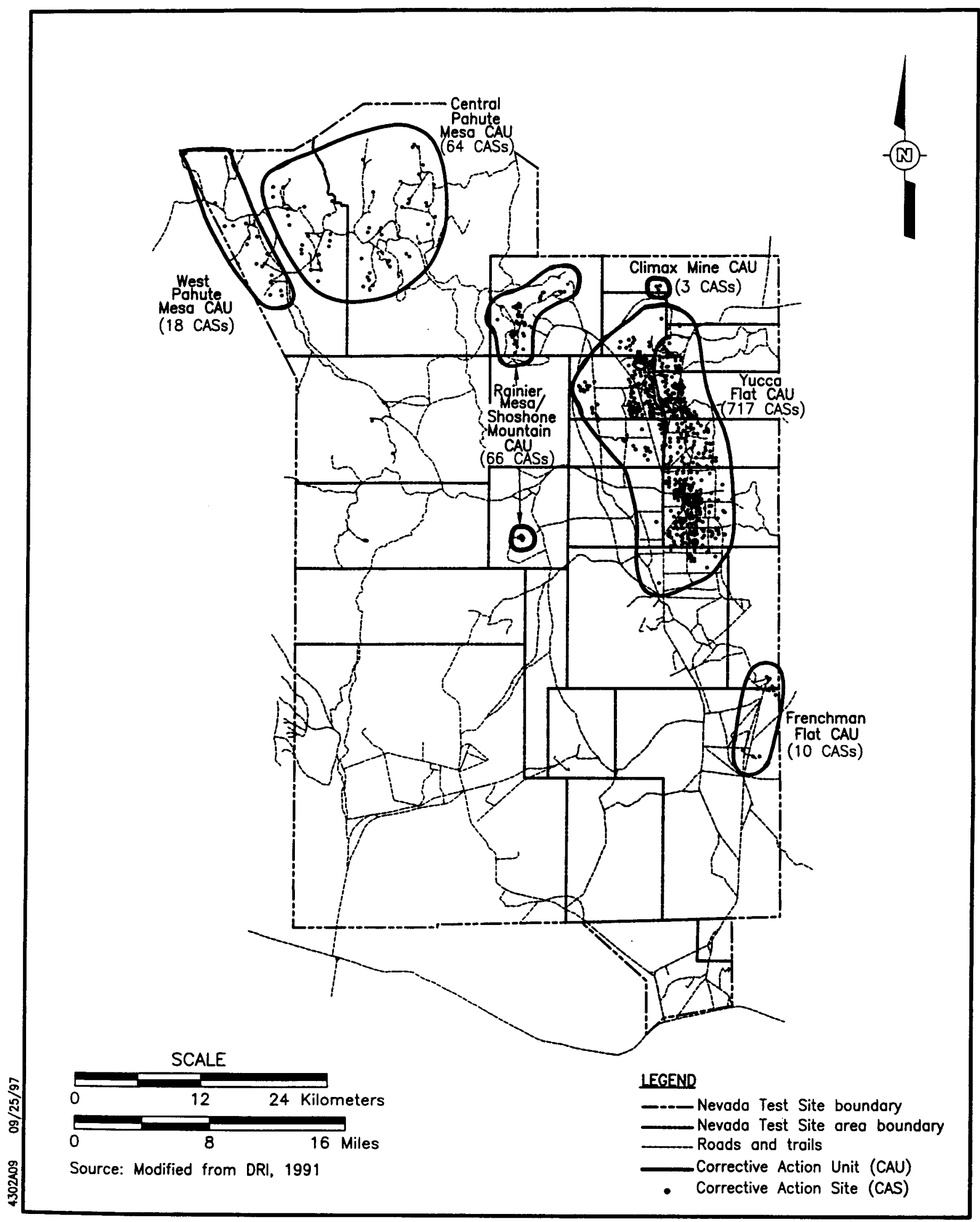

Figure 1-1

Underground Test Area Corrective Action Units 
of the strategy for underground nuclear test sites is to define boundaries around each CAU which establish areas containing water that may be unsafe for domestic and municipal use. This will be achieved by modeling groundwater flow and transport and by estimating the movement of contaminants using CAU-specific hydrogeologic data. The process is illustrated by the flow chart in Figure 1-2. The shaded portion of the diagram illustrates the portion of the process that will take place during the Corrective Action Investigation. The role of modeling in the process of creation of the Corrective Action Decision Document (CADD) is described next.

\subsubsection{Role of Modeling in the FFACO Process}

The CAU model is a tool that simulates the transport of contaminants in the groundwater flow system based on the most recent conceptual model. The CAU model will be deterministic, but will allow stochastic inputs to account for parameter and model uncertainties. The model simulates the concentration of contaminants downgradient of the underground test areas. The location of the contaminant boundary, along with the accompanying uncertainty in that boundary location, is then derived from the modeled concentration results. The contaminant boundary identifies portions of the groundwater system that have been contaminated above a level defined by negotiations between the U.S. Department of Energy (DOE) and the State of Nevada.

The FFACO process flow diagram for Underground Test Area Corrective Action Units is given in Figure 1-2. The assessment of CAU-related existing data, in turn, provides data for the CAU model. The simulated contaminant concentrations and associated uncertainty are reviewed by the DOE, and if the model is acceptable to DOE, a contaminant boundary is calculated and presented to the Nevada Department of Environmental Protection for approval. If approved, a CADD is prepared which defines the remedial alternative for the CAU. The remedial alternative leads directly to the Corrective Action Plan (CAP), which is the first step in the remediation process.

The CAU model can be used for several key components of the FFACO process in Figure 1-2 to:

- Simulate contaminant concentrations downgradient of underground test locations based on the most recent conceptual model of the NTS groundwater flow system.

- Estimate the uncertainty in the predicted concentrations.

- Simulate the maximum extent location of the contaminant boundary using the simulated concentrations based on the agreed upon boundary definition. 


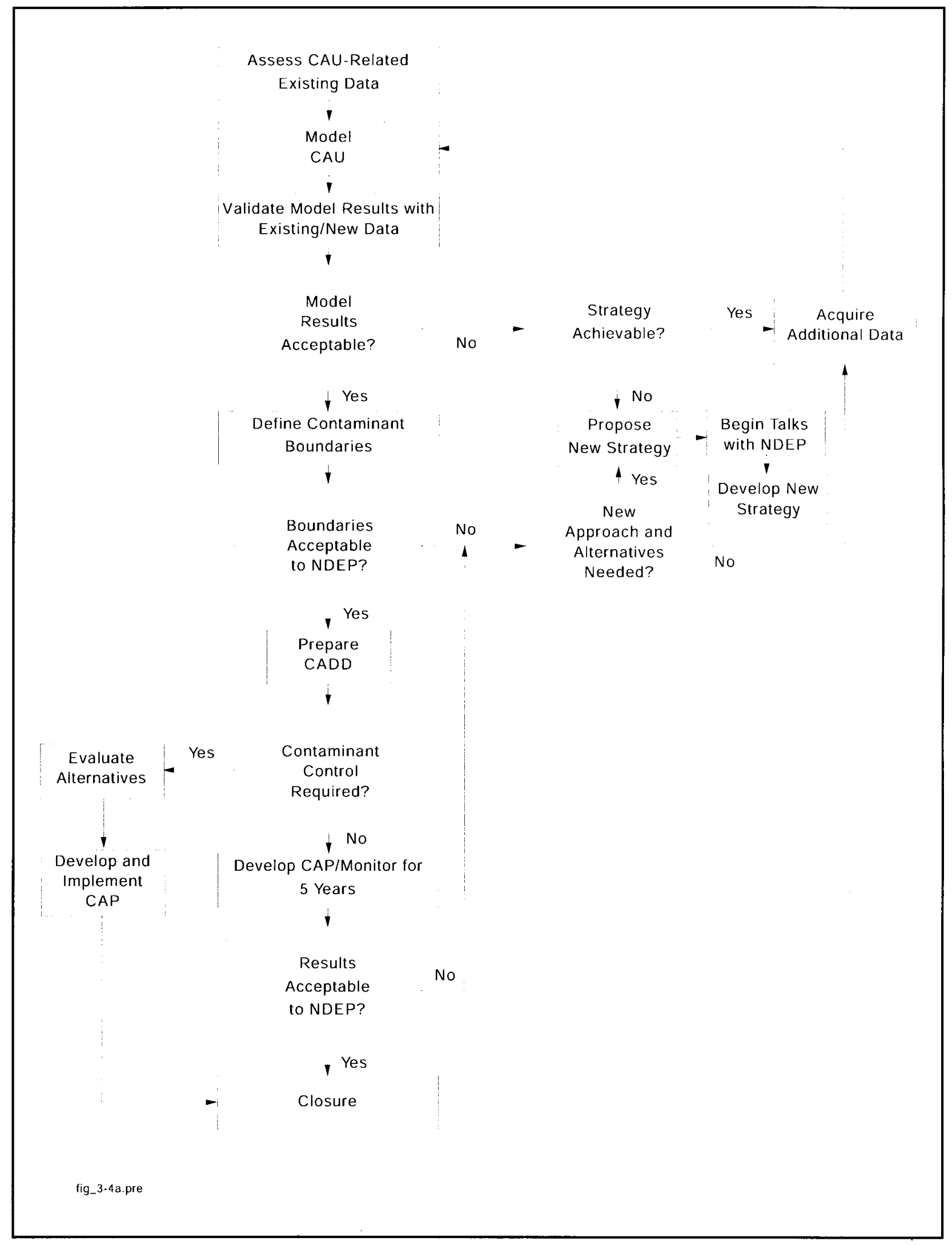

Figure 1-2

Process Flow Diagram for the Underground Test Area Corrective Action Unit 
- Estimate the uncertainty in the simulated boundary location.

- Assess the effectiveness of a remedial alternative.

- Predict the impact of future water resource allocations on the location of the contaminant boundary.

\subsection{Participating Agencies and Their Roles}

Several agencies will participate in the CAU modeling process. These agencies include IT Corporation (IT)/HSI-GeoTrans, Bechtel Nevada (BN), Desert Research Institute (DRI), Los Alamos National Laboratory (LANL), Lawrence Livermore National Laboratory (LLNL), and the U.S. Geological Survey (USGS). The agencies will provide input parameters to the flow and transport modeling and additional support to the Corrective Action Investigation. They will also participate in a Modeling Subcommittee via the Technical Working Group.

A Modeling Subcommittee of the Technical Working Group Committee was formed to assist in the development and usage of the CAU models. Subcommittee members will act as advisors on CAU modeling matters and as internal reviewers as well. Members of the Modeling Subcommittee will also participate in defining the general and CAU-specific modeling approaches which includes a rigorous and unbiased code selection. They also serve as peer reviewers of the modeling approach documents and reports. The Modeling Subcommittee is an integral part of the modeling process to ensure the validity of the approach used and the modeling results.

\subsection{Document Organization}

This section outlines the contents of the document and summarizes the contents of the sections which are described as follows:

- Section 1.0 is the introduction.

- Section 2.0 contains a description of the CAU model including the model objectives, a definition of the contaminant boundary, the requirements of a CAU model, a description of the conceptual model, the numerical code selection process, and the interactions with other models.

- Section 3.0 describes the CAU model development process including the grid system, boundary conditions, initial flow conditions, initial source term conditions, model calibration, and sensitivity analyses.

- Section 4.0 includes a description of the assessment of uncertainty. 
- Section 5.0 presents a summary of the modeling approach.

- Section 6.0 is a list of references used. 


\subsection{Corrective Action Unit Model Description}

A general description of the CAU model is provided in this section. The objectives of the model are presented, followed by the definition of the contaminant boundary and the specific requirements of the model. The steps necessary in the creation of the model are then described. The creation of the CAU model begins with a data analysis phase that leads to the development of the conceptual model of groundwater flow and transport, which includes the definition of the source term. The selection of an appropriate code will ensure that all physical and chemical processes of importance in the CAU are included in the model. Finally, the interaction of the CAU model with other larger and smaller scale models is explained.

\subsection{Model Objectives}

The numerical model selected for the CAU scale simulations will be required to meet the following objectives:

- Simulate flow and transport in the geologic units of a CAU to estimate the concentration of contaminants in space as a function of time up to 1,000 years.

- Derive a contaminant boundary from the modeled concentrations and assess the uncertainty in the contaminant boundary.

- Provide a tool to assess the effectiveness of future remedial designs.

- Use the model as a tool to evaluate the effects of future groundwater flow-system changes.

\subsection{Contaminant Boundary Definition}

The radionuclides released to the groundwater as a result of underground nuclear testing have contaminated the groundwater system over a specific volume. The amount of groundwater contaminated is a function of time. The degree of groundwater contamination may be expressed in terms of concentrations of specific radionuclides, amount of radioactivity, or radioactive dose, and the contaminant boundary definition will be a specific value tied to one of the contamination definitions. At the time of the writing of this document, a definition was not finalized. For all cases, the boundary will be calculated as some function of the simulated concentrations.

It is currently anticipated that the contaminant boundary will be defined as the location where a given cumulative dose to a human occurs. A simple drinking water ingestion scenario will be 
used to calculate a multiplicative factor to convert a simulated concentration to a dose to a human for each radionuclide. The dose at the contaminant boundary (or the boundary dose) is then calculated as the sum of the doses of all radionuclides that reach the boundary. The dose defining the contaminant boundary is currently set at 4 millirem per year at the 50 percent level, over a maximum period of 1,000 years. However, it is not necessary to define this dose prior to the start of CAU modeling, because the concentrations must be simulated before the dose can be calculated.

The location of the boundary will be examined for all time steps within the 1,000-year simulation period. Multiple computer simulations of the fate and transport of various radionuclides will be required to generate the concentration data necessary to calculate the contaminant boundary dose. Variable radionuclide source concentrations, leach rates, and mobilities will lead to a contaminant boundary that changes in space and time.

A significant issue with regard to the boundary is the question of uncertainty. A number of inputs to the CAU model are uncertain and will lead to uncertainty in the predicted concentrations and, hence, uncertainty in the contaminant boundary location. The analysis of this uncertainty will also be part of the contaminant boundary calculations. If the uncertainties in a particular input can be described by a probability distribution, the resultant uncertainty in the predicted boundary location can be estimated using a Monte Carlo analysis. In this approach, parameter input values will be generated from probability distribution functions (PDFs) and used to simulate the concentrations in the groundwater system. For each simulation, a contaminant boundary will be calculated and the resulting PDF of the boundary location will summarize contaminant boundary uncertainty.

The uncertainty in the simulated boundary location will be a function of many different variables and factors. Each of these sources of uncertainty will be evaluated to provide an assessment of the full range of boundary location uncertainty. Some sources of uncertainty are not easily amenable to Monte Carlo analyses. For example, different geologic interpretations of the aquifer system are typically represented by a small number of discrete alternatives rather than a continuum of values. These discrete alternatives will be simulated individually. For each alternative, the boundary location calculated from the simulated concentrations will be compared with boundary PDFs of the Monte Carlo analyses. 


\subsection{Requirements for a CAU-Scale Model}

The first objective requires the CAU model to have the ability to represent the important physical and chemical features of the CAU flow system. The features will include faulting, stratigraphy, sources and sinks of water, the distribution of contaminants, their rates of introduction into the groundwater flow system, and other physical or chemical features unique to the CAU. The second objective requires the model to be able to simulate the movement of a variety of contaminants which distributions and abundance serve to define the contaminant boundary. The third and fourth objectives require flexibility in the CAU model to allow grid changes, placement of additional wells, and boundary-condition variations. These requirements will be later expanded into a list of desired code capabilities.

\subsection{Groundwater Flow and Transport Conceptual Model}

The key physical and chemical features and processes that must be simulated by the CAU-scale model will be identified during the conceptual model phase of the modeling. The conceptual model describes the controls on the groundwater flow and provides a description of the anticipated movement of contaminants within the groundwater flow system of the CAU. The conceptual model includes a description of the geologic features that control flow (such as structure and stratigraphy), the hydraulic features that control flow (such as the permeability of various hydrostratigraphic units), and the sources and sinks of water. The transport portion of the conceptual model includes the location and form of the contaminants of concern, the chemical and physical conditions of the hydrostratigraphic units that impact the contaminant mass transport via advection, dispersion, diffusion, colloidal transport, and adsorption, as well as the chemical composition of the contaminants and the physical system that affects speciation and mobility.

The conceptual model will be defined after an analysis of the existing CAU-scale data has been completed. The existing data will include data compiled in support of the regional flow model, reinterpretation of existing data to include CAU-scale details, and inclusion of new data or interpretations. The specific data sources will be defined on a CAU basis. It is anticipated that the conceptual model will identify the hydrogeologic units, establish the importance of structural features such as faults, describe the groundwater flow direction, provide preliminary values for aquifer parameters, identify the important physical features such as fracture flow, and establish the chemical interaction of the hydrostratigraphic units with the contaminants of concern. An additional feature of the conceptual model is the hydrologic source term that describes the initial abundance of contaminants in, and the rate of the introduction into, the flowing hydrologic regime. 
The source term describes the spatial and temporal distribution of contaminants in the groundwater system. There is a clear distinction between the radiological source, which is the total inventory of radionuclides and other contaminants associated with an underground test, and the hydrologic source term, which describes the contaminants in the groundwater. The hydrologic source term is always smaller than the radiological source term and is currently being defined. The primary focus will be underground tests that were located near or below the water table. The definition of near the water table is specified to be a fixed distance of one hundred meters. Alternative approaches are available for evaluating the effects of underground tests located above the water table. The contaminants may be assumed to be trapped within the unsaturated zone and ignored while considering the saturated zone. Alternatively, the contaminant could be assumed to migrate toward the water table at a slow rate and could be included as a source at the water table at a later time. Another approach could be to assume the entire source term resides beneath the water table.

The source term is mostly constrained within the test cavity and the collapse chimney that forms above the cavity. Shortly after detonation, the different radionuclides become concentrated in specific regions of the test cavity and chimney. Borg et al., 1976, and Kersting, 1996, describe the spatial distribution of radionuclides in the cavity and chimney largely as a function of the volatility of the radionuclide or of a parent radionuclide which existed early in the formation of the cavity and chimney. Elements with high boiling points, or refractory elements, are concentrated in the melt, whereas radionuclides with lower boiling points, or volatile precursors, tend to disperse into the chimney rubble.

Complicating the spatial distribution is the transfer of contaminants to groundwater. Shortly after the detonation of the nuclear device, groundwater originally in place in the vicinity of the emplacement hole is promptly removed and injected in subsurface geologic strata located around the cavity generated by the detonation. Subsequently, the displaced groundwater moves back to where it used to be, before the detonation, into the newly-formed cavity and chimney. Most of the tritium is expected to be mixed with this water within approximately one year after the cavity fills. Other nonrefractory elements are expected to be sorbed to rubble material and will be available to the groundwater over a long period of time via complex chemical interactions of the rubble material, groundwater, and the specific contaminant of interest. Approximately 99 percent of the refractory elements will be incorporated in the melt glass. The elements in the melt glass may be released slowly over time via complex leaching and chemical processes. 
For the CAU model, the source term will include two components: 1) an instantaneous component with radioactivity in the cavity fluids at the time water begins to flow away from the cavity, and 2) a leaching source term that releases radioactivity from the rubble and melt glass over a period of time. The individual radionuclides and concentrations will need to be identified for each component.

\subsection{Numerical Code Selection}

It is advantageous to select a code that could be used for all CAUs. This would provide consistency in modeling one CAU to the next and would lead to efficiencies in the creation of each CAU model. The capabilities of the selected code are defined using the assumption that all CAUs could be simulated with the chosen model. Therefore, the selected code will need to have the following capabilities categorized under "general," "flow model," and "transport model:"

\section{General}

- Fully three-dimensional

- Ability to simulate large number of nodes (100,000 nodes or more)

- Established pre- and post-processors

- Steady-state and transient conditions

- Ability to accept multiple data sets for Monte Carlo simulations

- Efficient solver

\section{Flow Model}

- Saturated groundwater flow

- Heterogeneous and anisotropic hydraulic conductivity

- Point/distributed sources/sinks of water

- Temperature dependence

- Ability to simulate complex geology

\section{Transport}

- Transport of solutes

- Advection, dispersion, adsorption, and matrix diffusion

- Radioactive decay, daughter products

- Temperature dependence

- Minimal numerical dispersion

- Transport of colloids 
The above physical and chemical processes will require a model that is three-dimensional to accommodate the three-dimensional geology, dispersion, and the interaction of plumes from different sources. Candidate codes and their capabilities are listed in Table 2-1. The codes that include dual porosity and matrix diffusion have a priority over those that do not. A finite-element model formulation is being proposed to better represent the irregular spacing of underground test cavities, well locations, and geologic boundaries. A preference for finite element places FEHM and BIOF\&T-3D as the leading candidates. However, all codes are included in the list because it may turn out that the finite-element codes have unacceptable limitations. Of the codes indicated, three will be chosen for further evaluation. The three codes will be tested for ease and flexibility of operation, option packages, and speed of simulation, using a sample problem. This testing of the three codes will be the final step prior to code selection. The formulation of the equations governing the transport model is not specified at this time. For example, the form of the adsorption term may be equilibrium or kinetic depending on the radionuclide of concern and the specific hydrostratigraphic unit (HSU) involved.

One common aspect of these codes is that each is powerful software capable of simulating a variety of conditions. Some of these codes include the capability to simulate flow and transport in the unsaturated zone, which is not a requirement of the CAU model. In addition, Reeves et al. (1994) note that several of these codes do not have a steady-state option. This could be a significant drawback during steady-state calibration because it would require a great deal of computer time for each run. Finally, the simulation time for a large problem on most of these codes may be too long to allow a large number of Monte Carlo simulation runs. 
Table 2-1

Candidate Groundwater Flow and Transport Codes and Their Capabilities

\begin{tabular}{|c|c|c|c|c|c|c|c|c|c|c|}
\hline Code Capability Code Name & 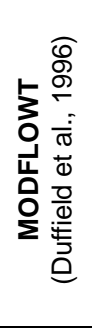 & 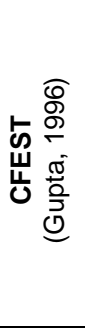 & 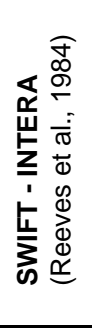 & 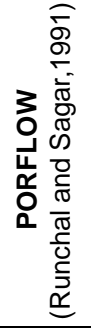 & 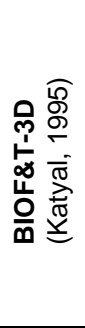 & 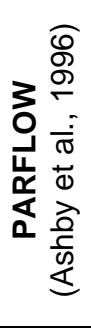 & 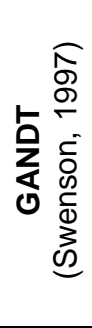 & 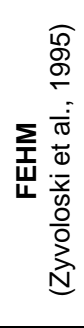 & 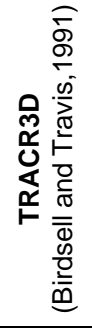 & 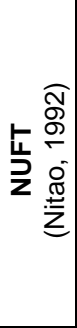 \\
\hline Formulation & $F D^{a}$ & $\mathrm{FE}^{\mathrm{b}}$ & FD & FD & $\mathrm{FE}$ & FD & FD & $\mathrm{FE}$ & FD & FD \\
\hline Groundwater flow and transport & $Y^{c}$ & Y & $\mathrm{Y}$ & Y & $\mathrm{Y}$ & Y & Y & Y & Y & Y \\
\hline Fully 3-D & Y & Y & $\mathrm{Y}$ & Y & $\mathrm{Y}$ & Y & Y & Y & Y & Y \\
\hline Heterogeneous & Y & $\mathrm{Y}$ & $\mathrm{Y}$ & $\mathrm{Y}$ & $\mathrm{Y}$ & $\mathrm{Y}$ & $\mathrm{Y}$ & $\mathrm{Y}$ & Y & Y \\
\hline Anisotropic & $\mathrm{Y}$ & Y & Y & Y & $\mathrm{Y}$ & Y & Y & Y & Y & Y \\
\hline Steady-state flow option & $\mathrm{Y}$ & $\mathrm{Y}$ & $\mathrm{Y}$ & $N^{d}$ & $?^{\mathrm{e}}$ & $\mathrm{Y}$ & $?$ & $\mathrm{~N}$ & $\mathrm{~N}$ & $\mathrm{~N}$ \\
\hline Transient flow & $\mathrm{Y}$ & $\mathrm{Y}$ & $\mathrm{Y}$ & $\mathrm{Y}$ & $\mathrm{Y}$ & $\mathrm{N}$ & $\mathrm{Y}$ & Y & $\mathrm{Y}$ & $\mathrm{Y}$ \\
\hline Point sources and sinks & $\mathrm{Y}$ & $\mathrm{Y}$ & $\mathrm{Y}$ & $\mathrm{Y}$ & $\mathrm{Y}$ & Y & $\mathrm{Y}$ & $\mathrm{Y}$ & $\mathrm{Y}$ & $\mathrm{Y}$ \\
\hline Dispersion & $\mathrm{Y}$ & $Y$ & $\mathrm{Y}$ & $\mathrm{Y}$ & $\mathrm{Y}$ & $\mathrm{Y}$ & $\mathrm{Y}$ & $\mathrm{Y}$ & $\mathrm{Y}$ & $\mathrm{Y}$ \\
\hline Adsorption & Y & Y & $Y$ & $Y$ & $Y$ & $Y$ & Y & Y & Y & Y \\
\hline Dual porosity/diffusion & $\mathrm{N}$ & $\mathrm{N}$ & $\mathrm{Y}$ & $\mathrm{Y}$ & $\mathrm{Y}$ & $\mathrm{N}$ & $\mathrm{N}$ & $\mathrm{Y}$ & $\mathrm{N}$ & $\mathrm{Y}$ \\
\hline Radioactive decay & $\mathrm{Y}$ & $\mathrm{Y}$ & $\mathrm{Y}$ & $\mathrm{Y}$ & $\mathrm{Y}$ & $\mathrm{Y}$ & $\mathrm{Y}$ & $\mathrm{Y}$ & $Y$ & $\mathrm{Y}$ \\
\hline Daughter products & $\mathrm{Y}$ & $\mathrm{N}$ & $\mathrm{Y}$ & $\mathrm{N}$ & $\mathrm{Y}$ & $\mathrm{N}$ & $\mathrm{N}$ & $\mathrm{N}$ & $\mathrm{Y}$ & $\mathrm{Y}$ \\
\hline Efficient modern solver & $\mathrm{Y}$ & $\mathrm{Y}$ & $\mathrm{Y}$ & $\mathrm{Y}$ & $\mathrm{Y}$ & Y & $\mathrm{Y}$ & Y & $\mathrm{Y}$ & $\mathrm{Y}$ \\
\hline Simulate large \# of nodes & $\mathrm{Y}$ & $\mathrm{Y}$ & $\mathrm{Y}$ & $\mathrm{Y}$ & $\mathrm{N}$ & $\mathrm{Y}$ & $\mathrm{Y}$ & $\mathrm{Y}$ & $\mathrm{Y}$ & $Y$ \\
\hline Preprocessor & Y & $\mathrm{Y}$ & Y & Y & $\mathrm{Y}$ & $\mathrm{Y}$ & Y & $\mathrm{Y}$ & $\mathrm{Y}$ & $\mathrm{Y}$ \\
\hline Postprocessor & $\mathrm{Y}$ & $Y$ & $\mathrm{Y}$ & $\mathrm{Y}$ & $\mathrm{Y}$ & $\mathrm{Y}$ & $\bar{Y}$ & $\mathrm{Y}$ & $\mathrm{Y}$ & $\mathrm{Y}$ \\
\hline Thermal effects & $\mathrm{N}$ & Y & $\mathrm{Y}$ & Y & $\mathrm{N}$ & $\mathrm{N}$ & $\mathrm{N}$ & $\mathrm{Y}$ & $\mathrm{N}$ & $\mathrm{Y}$ \\
\hline Stochastic input & $\mathrm{N}$ & $\mathrm{N}$ & $\mathrm{N}$ & $\mathrm{N}$ & $\mathrm{N}$ & $\mathrm{Y}$ & $\mathrm{Y}$ & $\mathrm{N}$ & $\mathrm{N}$ & $Y$ \\
\hline Source code & $\mathrm{Y}$ & $\mathrm{Y}$ & $\mathrm{Y}$ & $\mathrm{Y}$ & $\mathrm{N}$ & $\mathrm{Y}$ & $\mathrm{Y}$ & $Y$ & $Y$ & $\mathrm{Y}$ \\
\hline Complex geology & $\mathrm{Y}$ & $\bar{Y}$ & $\mathrm{Y}$ & $Y$ & $\mathrm{Y}$ & $\mathrm{Y}$ & $Y$ & $Y$ & $Y$ & $\mathrm{Y}$ \\
\hline
\end{tabular}

${ }_{b}^{a} F D$ : Finite difference

FE: Finite element

CY: Yes

$\mathrm{e}_{\mathrm{N}}^{\mathrm{d}}$ : No

?: Unknown 


\subsection{Interaction With Other Models}

Three other models will be run in support of the CAU model: the regional flow model (DOE, 1997), the DRI random field generator, and the LLNL hydrologic source term model, currently under development (Pohlmann and Andricevic, 1994). The regional flow model provides the boundary fluxes necessary to insure that the CAU model is consistent with the regional flow system. The DRI random field generator creates realizations of spatially variable parameters that will aid in assessing uncertainty in the simulated contaminant boundary. The LLNL hydrologic source term model provides the spatial distribution, release rates, and near source mobility of a variety of radionuclides.

\subsubsection{Regional Groundwater Flow Model}

The regional model (DOE, 1997) provides the necessary regional framework within which the CAU model operates. To create a valid result, the groundwater flow through the CAU model must be in balance with the regional model predictions. The refinements to the CAU geologic model may perturb the regional flow with respect to the current regional model. In addition, the CAU geologic model may define HSUs that are unknown in the regional model. Flow parameter values for the new HSUs must be assigned in conjunction with the overall regional flow system to be consistent with the flow parameters that presently exist in the regional model. For example, the hydraulic conductivities of the HSUs in the regional model were determined by calibration within bounds constrained by field measurements. To provide consistent information, a similar approach will be used for any new HSUs added as a result of the CAU scale geologic model. This will require replacing the geology in the vicinity of the CAU area within the regional model with the revised CAU geologic model. It is required that the regional geologic model at the border of the CAU model will be modified to remove any boundary inconsistencies. Regional flow simulations with the revised geologic model will be performed and will require some additional calibration. The final calibrated regional model will provide the necessary boundary and initial conditions for the CAU-scale simulations.

\subsubsection{DRI Random Field Generator}

Natural geologic formations are heterogeneous meaning their compositions, structure, physical properties, and chemical characteristics vary in space. This spatial variability cannot be measured in sufficient detail to provide data at all the locations of interest. The statistical description is used to create equiprobable representations of the parameter values using a Monte Carlo-type technique. Each of these representations, or realizations, is one possible model of the true subsurface variability. By examining many of these realizations, a statistical evaluation of the 
possible outcomes is performed. By examining the flow field in each of these realizations, it is possible to derive estimated values of effective parameters, such as dispersivity, at scales appropriate for the CAU-scale model. The random field generated by the DRI team may also be scaled to fit the CAU-scale simulations.

Researchers at the DRI have been using stochastic representations of the spatial variability to statistically describe the variation of the parameter values. The DRI will continue the development of random field generators for each of the CAUs.

\subsubsection{LLNL Source Term Model}

The source term simulations currently underway at LLNL for Frenchman Flat will provide data for selected contaminants about the distribution of elements in the melt glass, in the water, and adsorbed to the earth materials within and near the event cavities. Similar work will be performed by LLNL in the future for the other CAUs. This information will be summarized in the transport simulations by identifying initial concentrations of the contaminants in the water in and around the event cavity. In addition, the leach rate for the contaminant from the melt glass and rubble will be included as a time-dependent contaminant flux in the source term. It is the intent of the CAU modeling team to work closely with the LLNL team to best utilize the results of the source-term simulations. 


\subsection{Corrective Action Unit Model Development}

The development of the CAU-scale model includes setting up a grid system; defining boundary conditions, initial flow conditions, and initial source term conditions; calibrating the model; and performing sensitivity analyses.

\subsection{Grid System}

The scale of the models will be on the order of a CAU and the region downgradient in which the contaminant boundary is likely to occur. For some CAUs such as Pahute Mesa, the area of the model could be as large as 45 kilometers $(\mathrm{km})$ (28 miles [mi]) x $60 \mathrm{~km}$ (37 mi). Grid cell sizes will vary over the model. In the vicinity of the underground tests, the horizontal and vertical spacing may be as small as tens of meters (tens of feet). The grid spacing will be larger near the boundaries of the model. The discussions about grid size are presented in the following text with the assumptions that a finite element mesh is being used. The reader will recall that finite-difference-based computer codes have not been eliminated from consideration. Therefore, descriptions of mesh sizes and variable spacing would also apply if a finite-difference-based computer code is selected. Specific grid-size specifications will be identified at the time of the CAU-model development.

The finite-element mesh will be a function of the particular features of each CAU. Large-scale features such as the lateral and vertical distribution of geologic layering and faults will be included in the geologic model. To the extent possible, the physical location of layers and faults will be represented by the finite-element mesh. This will provide the maximum level of accuracy regarding contaminant movement near potentially important geologic boundaries by allowing the fault-zone hydraulic properties to be assigned independently of the HSU properties.

The precise features of each mesh can be defined only when the work begins for each CAU. Nonetheless, several criteria will be applied to each CAU in defining the finite-element mesh.

A. The external boundary of the CAU model will be rectangular to correspond to appropriate cell boundaries within the regional flow model. In this way, the flux distribution across a boundary of the regional model will be applied to the appropriate CAU-model boundary locations.

B. Finite-element nodes will be placed at each underground test location as well as at specific well locations. 
C. Finite-element nodes will be placed along faults that are identified as being important to the distribution of hydrostratigraphic units.

D. The mesh density will be greatest in the vicinity of the underground tests and at other points of interest such as discharge wells.

E. Other mesh nodes will be preferentially placed along HSU contacts to more precisely incorporate the geologic model structure in the simulations. The nodes will not be layered in the finite-difference sense, but instead will form a pattern representative of the CAUscale geology.

F. The total number of nodes is not yet defined, but the nodal spacing will be as small as a few tens of meters (m) (tens of feet) in the vicinity of event cavities and wells to as much as 1,500 meters $(4,920$ feet $[\mathrm{ft}])$ at the boundary.

The number of nodes in the CAU model will be constrained by the computational ability of the computer hardware. The greater the number of nodes, the longer the computer run times become. The primary focus of the grid design will be to ensure that the fundamental physics of the problem are simulated. If compromises in the total number of nodes are required, they will be made in regions away from the test cavities and downgradient locations.

\subsection{Boundary Conditions}

The boundary of the CAU-scale model will correspond to a predefined portion of the regional groundwater-flow model. The flux distribution and total flux across the regional border will need to be the same as the flux distribution and total flux into the CAU-scale model along the same border. It is anticipated that the CAU-scale geologic model will differ from the regional geologic model at the same location. In addition, the regional flow model is defined on the basis of flowmodel layers which often do not correspond to geologic-model layers. The external boundaries of the CAU-scale model will be specified flux conditions as defined by the regional flow model. The corresponding regional flow model flux will be apportioned to the CAU model boundaries on the basis of hydraulic conductivity times the area values assigned to the CAU-model cells along the boundary.

Horizontally, the external boundaries of the CAU-scale model will coincide with selected rows and columns of the regional finite difference model. The nodal spacing will be no greater than the regional model cell size $(1,500 \mathrm{~m}[4,920 \mathrm{ft}]$ per side $)$. In the vertical direction, it is expected that the HSU boundaries of the CAU-scale model will not match the flow model layer elevations of the regional flow model. As a result, a flux allocation approach will be employed whereby the 
total flux across a regional model cell is apportioned to the corresponding CAU nodes on the basis of connecting element hydraulic conductivity times area. The external boundaries of the CAU model will be treated as constant flux, using the fluxes derived from the regional groundwater-flow model.

It is anticipated that the CAU geologic model and the regional geologic model will be inconsistent at the boundary of the CAU model. These boundary inconsistencies need to be resolved in the CAU model by modifying the regional geologic model in some small region around the CAU model to remove inconsistencies between the two geologic models. The CAU geologic model will then be inserted into the regional geologic model. It is important to realize that within the $\mathrm{CAU}$, this process will replace the regional geologic model with the updated CAU geologic model. This ensures that the regional flow model contains the most current information. The additional detail in the CAU geologic model will, in all likelihood, alter the regional flow in the vicinity of the CAU. For the boundary fluxes to be valid for CAU simulation, the fluxes must be consistent with the CAU geologic model by simulations of the regional-flow model with the updated geologic model. This has the additional advantage that the modified regional-flow model will be fully capable of simulating the impact of external water resource decisions on the CAU boundary fluxes. Changes to the simulated contaminant boundary location can then be identified using the CAU model and the modified boundary fluxes.

The bottom of the model will be treated as a no-flow boundary, similar to the treatment in the regional model. Finally, the recharge will be initially defined as in the regional model with the option of modifying its distribution to account for basin margin recharge and for recharge into event craters.

\subsection{Initial Flow Conditions}

The initial heads in the CAU model will be calculated by interpolating the regional flow model heads. Therefore, the initial conditions for the CAU simulation will be the steady-state heads from the regional groundwater-flow model. Calibration of the CAU-scale flow model will be required to match simulated hydraulic heads to the measured heads. The measured hydraulic head data will be derived from existing potentiometric data. This steady-state flow system will then become the initial condition for transient flow and transport simulations. The transient flow and transport simulations will include the effects of water well pumping and the sequence of underground test. 


\subsection{Initial Source Term Conditions}

The initial concentration data will be derived from the work to be performed at LLNL. It is anticipated that LLNL will provide the following source data:

- The spatial distribution of the source term in and near the event cavity

- The concentration of radionuclides dissolved in the groundwater

- The leach rate for radionuclides currently incorporated into the melt glass

- The release rate of sorbed radionuclides in the rubble

- The mobility of radionuclides in the cavity, fracture zone, and undisturbed zone

This information will be used, in part, to identify the radionuclides of concern based on concentration, release rate, and mobility. The scale of the CAU model will be larger than the source-term model. The spatial distribution of radionuclides will be integrated in the CAU model to preserve total mass. The release rate from the rubble zone and cavity will be summarized in terms of a total mass flux, again to preserve the total mass exiting the cavity and chimney.

\subsection{Model Calibration}

Calibration of the CAU model is the process of matching historical data and is usually a prerequisite for making predictions with the model. Calibration refines the modeled representation of the hydrogeologic framework, hydraulic properties, and boundary conditions to achieve a desired degree of correspondence between the model simulations and observations of the groundwater flow system. The flow model will be calibrated using the manual (trial-anderror) method.

The simulated results will be compared to site-specific information such as measured hydraulic heads or estimated fluxes. The amount of head and flux data will vary from one CAU to the next. Typically, only head data will be available, the exception being Western Pahute Mesa where flux data for discharge at Oasis Valley are available from the USGS. In CAUs without measured fluxes, the constraints provided by the regional model become more important. The regional model contains flux constraints that will translate to fluxes at the CAU boundary. The proposed process of updating the regional groundwater flow model during the CAU-scale modeling will provide flux constants that will aid in the calibration of the CAU-scale model.

The calibration will produce quantitative and qualitative measures of the degree of correspondence between the simulation and site-specific information related to the physical hydrogeologic system. The degree of correspondence between the simulation and the physical hydrogeologic system can then be compared to that for previous simulations to ascertain the 
success of calibration efforts and, if needed, to identify potentially beneficial directions for further calibration efforts.

There will be a two-step calibration process for the CAU modeling. First, a preliminary calibration of the regional model will be performed after the enhancements to the geologic model are complete. This calibration is necessary to provide boundary conditions for the CAU model. The steady-state CAU model will also need to be calibrated. The amount of detail in the CAU model will allow for more refinement of the flow system and is expected to produce a better calibration to the CAU flow system. Within the CAU calibration, there may need to be several adjustments to the regional model as parameter values change in the CAU model. This will continue to ensure consistency between the regional and CAU models.

Calibration targets will be established for both models. The regional model targets will be the same as those used in the regional model (IT, 1996) and will include both hydraulic heads and discharge fluxes. The CAU model will also have hydraulic head and flux calibration targets, as appropriate. The specification of the CAU model boundary fluxes and the lack of internal natural discharge locations in several of the CAUs may eliminate discharge flux as a calibration target in some cases. However, the CAU model will always be contained by the regional model which includes regional discharge fluxes.

After the above steady-state calibration process is completed, a transient calibration will be implemented to verify the steady-state result. In the transient calibration, the drawdown from pumping wells and other hydraulic transients will be simulated. The effectiveness of the transient calibration will depend on the availability and accuracy of groundwater discharge data. The utility of the transient simulations will be dependent on the ability of the CAU model to simulate small scale processes recognizing that scale consideration related to the scale of the model grid and the drawdown measurements must be considered. The success of the CAU model will depend on testing it against the known conditions within the CAU, and these will include transient effects.

In addition, any available radionuclide concentration data from groundwater in a particular CAU will be evaluated as additional targets in the calibration of the transport model. This could include tracer test data, such as at the BULLION site, or observed migration of radionuclides such as at the CAMBRIC and CHESHIRE sites. The amount of concentration data is generally quite limited, but every attempt will be made to include existing data. Again, this provides another 
known condition within the CAU with which to evaluate the effectiveness of the CAU model. As with hydraulic heads, scale effects on concentration will need to be considered.

The groundwater flow and transport model will be calibrated using the American Society for Testing and Materials standard ASTM guidance for calibrating groundwater models. The Standard Guide for Calibrating a Ground-Water Flow Model Application (Brown and Laase, 1995) is a guide for calibrating porous medium (continuum) groundwater flow models. The method can be adjusted to use on other types of groundwater models such as multiphase models, noncontinuum (karst or fracture flow) models, or mass transport models.

The American Society for Testing and Materials (ASTM) standard procedures will be used to implement the guidance. These procedures cover the use of site-specific information (D5490), applying modeling to site-specific problems (D5447), defining boundary (D5609) and initial (D5610) conditions, performing sensitivity analyses (D5611), and documenting groundwater flow model applications (D5718) (ASTM, 1993; 1994a,b,c; ASTM, 1995).

\subsection{Sensitivity Analyses}

The purpose of the sensitivity analyses will be to calculate the change in the model calibration due to changes in parameter values. A systematic process will be implemented whereby a parameter is increased and then decreased by a constant factor from the calibrated value and additional simulations performed to identify the change in calibration residuals.

The range of values will be a function of the range of uncertainty of each parameter. Up to two values above and below the calibrated value will be selected. The outcome of these sensitivity analyses will determine which variables are most important to the simulations and will focus the selection of the variables for the Monte Carlo analyses. 


\subsection{Assessment of Uncertainty}

Uncertainty in this context refers to the uncertainty in the location of the contaminant boundary for the CAU. The location of the contaminant boundary is simulated using models; therefore, any uncertainty in the geologic model, source term, parameter values, or boundary conditions is a potential source of contaminant boundary uncertainty. In addition, the definition of the contaminant boundary itself, if subject to change, is also a source of uncertainty.

Geologic model uncertainty comes from the fact that information used to characterize subsurface structure, composition, or behavior is always incomplete. Professional geologists extrapolate between locations of known information such as outcrops, boreholes, or surface geophysical arrays. The CAU geologic model is then created from the geologists' interpretations. Part of the geologic-model process includes a peer review of the final geologic model. This process ensures that the CAU geologic model is the best available assessment of the subsurface stratigraphic and structural relationships. Nonetheless, there will always be some uncertainty in the geologic model due to the extrapolation that occurs during the model creation.

To account for this uncertainty, several alternative interpretations of the subsurface geology will be requested from the geologists who created the geologic model. The alternative geologic models will correspond to different hydrologic parameter distributions. The alternative geologic models will be converted to hydrologic parameter changes that will be incorporated into the CAU groundwater-flow model. For consistency, these same changes may need to be included in the regional model. For example, if the alternative interpretation causes a confining unit to be an aquifer unit, the hydraulic conductivity of the unit will be increased to mimic the effect of an aquifer. Alternatively, the uncertainty of certain features of the geologic model, such as the elevation of a contact between two HSUs could be handled via a Monte Carlo approach using the DRI spatially correlated random field generator to provide alternative realizations. In this way, the impact of an alternative geologic interpretation can be investigated without the costly and time-consuming process of creating a completely new geologic model.

The source term as used in the CAU model will be a simplification of the more detailed source term being generated by LLNL. The simplification of and any imprecision in the LLNL calculations will produce uncertainty in the source term. The initial distribution of radionuclides and the release rate from the melt glass and rubble are subject to uncertainty. Comments from source term experts will be solicited to provide plausible ranges of values for the source term 
components. These ranges will be used to assess the impact of source term uncertainty on the migration of contaminants in the subsurface.

Parameter value uncertainty comes from several sources and varies with the scale of the measurement. One source of uncertainty is limited data with which to estimate parameter values. A second source of uncertainty is due to parameters that vary spatially in geologic units. Uncertainty due to limited data is considered reducible because additional data collection will provide better estimates of the mean value. Spatial variability is an irreducible uncertainty because limited data collection does not provide sufficient information to define the spatially variable parameter in much detail.

This spatial variability occurs over many scales from pore size to the size of an entire basin. Spatial variability leads to uncertainty in local groundwater velocity and direction of flow. For a given zone of radionuclide contamination emanating from a test location, the impacts of localscale variabilities serve to define a mean velocity and direction of plume migration as the radionuclides move farther from the source. The small-scale variability also produces plume-scale responses such as dispersion and retardation that may be important in the assessment of the contaminant boundary. Quantifying the effect of the uncertainty is necessary to provide the DOE and other stakeholders with the knowledge they need to make informed decisions regarding the closure of CAUs. Researchers at the DRI (Pohlmann and Andricevic [1994] and Shirley et al. [1996]) have developed methods to describe the spatial variability and to create realizations of spatially variable parameters that can be used in modeling. Methods to quantify spatial variability, such as the ones developed by the DRI, will be incorporated as part of the CAU model development.

In addition, a certain amount of spatial averaging that is part of the application of the numerical model to a flow system always exists. Generally, the value of a parameter is often constant over several to many elements in a numerical model. These groups of elements are called zones and are regions of the model with similar properties that represent the mean value of the parameter in that region. The mean value of a parameter in any particular zone is not known with certainty. The amount of uncertainty depends on the amount of variability and the number of measurements available.

One approach to incorporate the DRI model data into the CAU-scale model is to integrate the small-scale property data over the size of the CAU-scale model. Therefore, near the sources, the 
resolution of the CAU-scale model will be similar to the resolution of the DRI model. There would be only a small amount of detail lost near the source. Farther away, where the discretization of the CAU model becomes coarse, the amount of detail lost would be greater because more upscaling would take place. Lost information could be incorporated into the modeling by increasing the uncertainty associated with certain parameters such as the dispersion coefficient.

A second approach to using the small-scale information generated by DRI is to have effective parameters calculated from the DRI realizations. The change in the second moment of the plume can be related to the dispersivity. For each DRI simulation, a different dispersivity could be calculated. Therefore, for all the runs a mean and variance of the dispersivity would be calculated. The derived mean and variance could then be incorporated into the transport model. If the effective parameter approach is used, then it must be recognized that the resulting concentration data will also have been averaged.

Parameter uncertainty is, therefore, the sum of a measurement uncertainty and a spatial variability uncertainty. If the contaminant boundary is far enough away from the source, then a significant amount of spacial averaging will take place. In that case, the effects of spatial variability can be incorporated into a variance term for the velocity and the direction of flow. If the distance to the boundary is small, then spatial variability will be more important and will need to be incorporated into the modeling directly via a random field generator. This will reproduce the aspects of the variability directly.

Boundary-condition uncertainty must also be considered. Two boundary conditions will be considered in the uncertainty analysis. One is the recharge component which will vary spatially and temporally. A second boundary uncertainty is the flux defined by the regional model. The magnitude and location of the flux is a function of the parameters used in the regional model. As a result, regional-model uncertainty will produce an uncertainty in the CAU model. Boundary uncertainty will be investigated by perturbing the parameter values within the regional model and observing the impact on the simulated contaminant concentration. This will effectively change the boundary fluxes, but not boundary locations.

Many sources of uncertainty have been identified in the discussion above. The approach to quantify the uncertainty in parameter values is via a probability distribution and the use of a Monte Carlo approach to generate parameter realizations that are used in the simulation model. 
The probability distribution of model response (contaminant concentrations) is derived from the simulation results and provides an assessment of uncertainty in the model predictions. The advantages of the Monte Carlo approach are that it is relatively straightforward to implement; it can account for correlated parameters; it can incorporate spatially correlated random variables; and it takes full advantage of the computational rigor of the CAU model. One disadvantage of the Monte Carlo approach is the computational burden of multiple simulations. This disadvantage can be reduced by selective sampling, such as via a Latin Hypercube Sampling technique to reduce the number of realizations. The Monte Carlo method can assess the uncertainty in the model predictions within the limitations of the selected conceptual model. If the conceptual model is in error, then it is possible that the true boundary location may not fall within the modeled uncertainty.

Assessment of sources of uncertainty that cannot be described by using a probability distribution will be included in a different manner. Some alternative interpretations of the geologic model, for example, will be described by a limited number of interpretations, not by a probability distribution. In this case, the simulation of contaminant concentrations for each alternative provides a quantitative change in a measure, such as the contaminant boundary, but it does not provide a probabilistic assessment in the way that the Monte Carlo approach can. The amount of change in the boundary location from an alternative geologic model will be compared with the Monte Carlo results to identify the comparable change due to parameter uncertainty. For example, if an alternative geologic model resulted in a 500-m (1,640-ft) change in the contaminant boundary, how would that compare with the change in the boundary location from the 50 percent to 75 percent level in the Monte Carlo analysis? If $500 \mathrm{~m}$ (1,640 ft) corresponded to 55 percent, then it would appear the uncertainty in the boundary location due to that alternative geologic interpretation is small. If the 500-m (1,640-ft) change was similar to the 90 percent case from the Monte Carlo simulations, then the alternative geologic interpretation would be considered more important. Other sources of uncertainty that cannot be described by a probability function, such as fault properties (barrier or conduit) or some aspects of recharge (mountain front, for example), will be treated in a similar manner. 


\subsection{Summary of the Modeling Approach}

The details of the modeling for each CAU will be defined at the time each CAU model is created. However, certain features will be consistent from one CAU to the next. The CAU model will be three-dimensional and will simulate the relevant physical and chemical processes in each CAU. The finite-element approach is currently the preferred method because of the flexibility to better approximate boundaries. However, as noted earlier, the use of a finite- difference code will not be ruled out until after the final code selection is made. The CAU model will be enhanced by interaction with the regional flow model, the DRI random field generator, and the LLNL source term model. Uncertainty in the model predictions due to parameter, source term, boundary, and geologic uncertainty will be assessed as part of the CAU-modeling effort. The final product will be a prediction of contaminant concentrations in groundwater which will be used to define a contaminant boundary. The uncertainty associated with the simulated boundary will be quantified and presented along with the boundary. 


\subsection{References}

ASTM, see American Society for Testing and Materials.

Ashby, S.F., C.H. Baldwin, W.J. Bosl, R.D. Falgout, R.M. Maxwell, and S.G. Smith and A.F.B. Tompson. 1996. Application and Implementation of the ParFlow Groundwater Flow Model, Extended Abstract UCRL-JC-125919. Livermore CA: Lawrence Livermore National Laboratory.

ASTM. 1993. Standard Guide for Application of a Ground-Water Flow Model to a SiteSpecific Problem, Designation D 5447-93. Philadelphia, PA.

ASTM. 1994a. Standard Guide for Comparing Ground-Water Flow Model Simulations to Site-Specific Information, Designation D 5490-93. Philadelphia, PA.

ASTM. 1994b. Standard Guide for Defining Boundary Conditions in Ground-Water Flow Modeling, Designation D 5609-94. Philadelphia, PA.

ASTM. 1994c. Standard Guide for Conducting a Sensitivity Analysis for a Ground-Water Flow Model Application, Designation D 5611-94. Philadelphia, PA.

ASTM. 1995. Standard Guide for Defining Initial Conditions in Ground-Water Flow Modeling, Designation D 5610-94. Philadelphia, PA.

Birdsell, K.H., and B.J.Travis. 1991. TRACR3D: A Model of Flow and Transport in Porous Media, LA-11798-M. Los Alamos, NM: Los Alamos National Laboratory.

Borg, I.Y., R. Stone, H.B. Levy, and L.D. Ramspott. 1976. Information Pertinent to the Migration of Radionuclides in Ground Water at the Nevada Test Site, Part 1: Review and Analysis of Existing Information, Report UCRL-52078. Livermore CA: Lawrence Livermore National Laboratory.

Brown, D.M., and A. Laase. 1995. Standard Guide for Calibrating a Ground-Water Flow Model Application, Section D18.21.10, Designation C-7, Draft No. 4. Philadelphia, PA: American Society for Testing and Materials.

DOE, see U.S. Department of Energy.

Duffield, G.M., J.J. Benegar, and D.S. Ward. 1996. MODFLOWT, A Modular ThreeDimensional Groundwater Flow and Transport Model, User's Manual Version 1.1. Sterling, VA: HSI GeoTrans, Inc.

FFACO, see Federal Facility Agreement and Consent Order. 
Federal Facility Agreement and Consent Order. 1996. Agreed to by the U.S. Department of Energy, the State of Nevada, and the U.S. Department of Defense.

Gupta, S. 1996. DFEST96, Flow and Solute Transport, Draft User's Manual. Irvine, CA: Consultant for Environmental System Technologies (CFEST).

IT Corporation. 1996. Groundwater Flow Model Documentation Package (Phase I Data Analysis Documentation, Volume VI). Prepared for DOE/NV. Las Vegas, NV.

Katyal, A.K. 1995. CSMoS Online Model Information for BIOF\&T-3D, U.S. Environmental Protection - Ada Oklahoma Laboratory. Blacksburg, VA: Draper Aden Environmental Modeling, Inc.

Kersting, A.B. 1996. The State of the Hydrologic Source Term, Report UCRL-ID-126557. Livermore CA: Lawrence Livermore National Laboratory.

Nitao, J.J. 1992. Main User's Manual for the NUFT Flow and Transport Code. Livermore, CA: Lawrence Livermore National Laboratory.

Pohlmann, K., and R. Andricevic. 1994. Identification of Potential Groundwater Flow Paths using Geological and Geophysical Data, Publication No. 45128. Las Vegas, NV: Desert Research Institute.

Reeves, M., D.S. Ward, and R.M. Cranwell. 1984. Theory and Implementation for SWIFT II: The Sandia Waste-Isolation Flow and Transport Model for Fractured Media, SAND83-1159. Albuquerque, NM: Sandia National Laboratories.

Reeves, M, N.A. Baker, and J.O. Duguid. 1994. Review and Selection of Unsaturated Flow Models, B00000000-01425-2200-00001, Rev. 00. Las Vegas, NV: INTERA, Inc.

Runchal, A.K., and B. Sagar. 1991. PORFLOW: A Model for Fluid Flow, Heat, and Mass Transport in Multifluid, Multiphase Fractured or Porous Media, User's Manual - Version 2.34, ACRi/016/Rev. E. West Los Angeles, CA: Analytical and Computational Research, Inc.

Shirley, C., K. Pohlmann, and R. Andricevic. 1996. Three-Dimensional Mapping of Equiprobable Hydrostratigraphic Units at the Frenchman Flat Corrective Action Unit, Nevada Test Site, Publication No. 45152. Las Vegas, NV: Desert Research Institute.

Swenson, K.B. Sandia National Laboratories. 1997. Personal Communication to K. Rehfeldt, IT Corp., Las Vegas, NV, regarding GANDT User's Manual, 10 July. 
U.S. Department of Energy. 1997. Regional Groundwater Flow and Tritium Transport Modeling and Risk Assessment of the Underground Test Area, Nevada Test Site, Nevada. Las Vegas, NV: IT Corporation.

Zyvoloski, G.A., B.A. Robinson, Z.V. Dash, and L.L. Trease. 1995. Models and Methods Summary for the FEHM Application, Document LA-UR-94-3787. Los Alamos, NM: Los Alamos National Laboratory. 
$\underline{\text { Copies }}$

Paul J. Liebendorfer 1

State of Nevada

Bureau of Federal Facilities

Division of Environmental Protection

333 W. Nye Lane, Room 138

Carson City, NV 89706-0851

Donald A. Garrepy

Bureau of Federal Facilities

Division of Environmental Protection

555 E. Washington, Suite 4300

Las Vegas, NV 89101

Robert M. Bangerter, Jr.

DOE/Nevada Operations Office

Environmental Restoration Division

P.O. Box 98518, M/S 505

Las Vegas, NV 89193-8518

Ward L. Hawkins

Los Alamos National Laboratory

P.O. Box 1663 - EES-1M/S D462

Los Alamos, NM 87545

Paul K. Ortego

Bechtel Nevada

2621 Losee Road

M/S NLV082

North Las Vegas, NV 89030

Gayle A. Pawloski

Lawrence Livermore National Laboratory

P.O. Box 808, M/S L-221

700 East Avenue

Livermore, CA 94550

Chuck Russell

Desert Research Institute

P.O. Box 19040, M/S 505

755 E. Flamingo Road

Las Vegas, NV 89132-0040 
David Smith

Lawrence Livermore National Laboratory

P.O. Box 808, M/S L-231

700 East Avenue

Livermore, CA 94550

Doug Trudeau

U.S. Geological Survey

Water Resources Division

6770 South Paradise Road

Las Vegas, NV 89119

Janet Wille

1

IT Corporation

2621 Losee Road, Bldg. B-1

M/S 439

North Las Vegas, NV 89030

U.S. Department of Energy

Office of Scientific and Technical Information

175 Oak Ridge Turnpike

P.O. Box 62

Oak Ridge, Tennessee 37831

U.S. Department of Energy

Technical Information Resource Center

DOE/Nevada Operations Office

P.O. Box 98518, M/S 505

Las Vegas, NV 89193-8518 